\title{
Occupational exposure to HIV among healthcare workers in PMTCT sites in Port Harcourt, Nigeria
}

Ndubuisi Akpuh ${ }^{1 *}$, IkeOluwapo Ajayi², Ayo Adebowale², Hadejia Idris Suleiman², Patrick Nguku', Mahmood Dalhat ${ }^{1}$ and Elizabeth Adedire ${ }^{1}$

\begin{abstract}
Background: Rivers State is among the states with high HIV prevalence in Nigeria. Occupational exposure to HIV through blood or body fluids of HIV/AIDS patients is a recognised risk factor of HIV infections among healthcare workers. We identified the determinants of occupational exposures to HIV among healthcare workers in Prevention of Maternal to Child Transmission (PMTCT) sites within Port Harcourt metropolis in Rivers State.

Methods: A descriptive cross-sectional study was conducted and multi-stage sampling technique was used to select 341 healthcare providers from 22 public and 22 private health facilities in PMTCT sites in Port Harcourt metropolis. The data collected were analysed using descriptive statistics, Chi-square and logistic regression models ( $p$-value $=0.05$ ).

Results: Respondents' mean age was 35.9 \pm SD8.4 years, 270 (80.1\%) and 171(50.7\%) were females, and from public health facilities respectively. Prevalence of occupational exposure of healthcare workers to HIV in the past 12 months was 153 (45.0\%), and 96 (63.3\%) experienced such exposure more than once. Contacts with potentially infectious body fluid accounted for the largest proportion 51 (33.3\%); followed by needle stick prick 49 (32.6\%). About 189 (56.1\%) had safety information at their disposal and this serves as a reminder on safety precautions. The likelihood of occupational exposure was significantly higher among doctors ( $A O R=2.22,95 \%$ C.I $=1.16-4.25$,) but lower among environmental health workers $(A O R=0.10,95 \% C . I=0.02-0.46$, ) than nurses $/$ midwives when other factors were included in the model.

Conclusion: Occupational exposure to blood and body fluids remains a frequent occurrence among healthcare workers; highest among doctors in PMTCT sites in the study area. Provision of protective safety materials, training and enforcement of adherence to universal precaution strategies are highly recommended.
\end{abstract}

Keywords: Occupational exposure, HIV, HealthCare workers, Private facility, Public facility, PMTCT, Port Harcourt, Rivers state, Nigeria

\footnotetext{
* Correspondence: drakpuh@gmail.com

${ }^{1}$ Nigeria Field Epidemiology and Laboratory Training Program (NFELTP), 50

Haile Selassie Street, Asokoro, Abuja, Nigeria

Full list of author information is available at the end of the article
}

\section{$\triangle B M C$}

(c) The Author(s). 2020 Open Access This article is licensed under a Creative Commons Attribution 4.0 International License, which permits use, sharing, adaptation, distribution and reproduction in any medium or format, as long as you give appropriate credit to the original author(s) and the source, provide a link to the Creative Commons licence, and indicate if changes were made. The images or other third party material in this article are included in the article's Creative Commons licence, unless indicated otherwise in a credit line to the material. If material is not included in the article's Creative Commons licence and your intended use is not permitted by statutory regulation or exceeds the permitted use, you will need to obtain permission directly from the copyright holder. To view a copy of this licence, visit http://creativecommons.org/licenses/by/4.0/ The Creative Commons Public Domain Dedication waiver (http://creativecommons.org/publicdomain/zero/1.0/) applies to the data made available in this article, unless otherwise stated in a credit line to the data. 


\section{Background}

Human Immunodeficiency Syndrome (HIV/AIDS) is one of the infectious diseases that threaten human survival [1]. Nigeria has the second largest number of people living with HIV/AIDS (PLHA) in Africa accounting for $9.0 \%$ of the global burden with prevalence of $3.2 \%$, and burden of 3.1 million people living with HIV. This burden impacts negatively on the health system [2]. Report of HIV research in Nigeria showed that Rivers State has the highest HIV prevalence (15.2\%) among the states in the country (National AIDS Reproductive Health survey, 2014) [3], but the latest National HIV/AIDS indicator survey places her in the third position in prevalence amongst 36 states and Federal Capital Territory (Federal Ministry of Health, 2019) [4]. Healthcare workers are exposed to infectioncausing organisms, including HIV as a result of caring for patients in the health care settings and this often places them at risk of infection [5].

Healthcare workers have become infected with HIV in caring for HIV patients [5] through accidental exposure to body fluids and percutaneous injury (needle stick or cut with a sharp object), contact of mucous membrane, or contact of skin (especially when the exposed skin is chapped, abridged, or afflicted with dermatitis [5-8]. Unfortunately, unavailability of protective equipment and or healthcare workers' refusal to use 'the safety equipment where available increases the risk of occupational exposure [9].

This study focuses on how health care workers are at higher risk of occupational infection compared to other healthcare workers in non-HIV specialised facilities [10]. It also focuses on specialized HIV care centres such as Prevention of Maternal to Child Transmission of HIV (PMTCT) sites in public and private settings [11]. This is because PMTCT sites are designated sites for HIV patients, and the care they receive during labour and child delivery almost certainly entail revealing body fluids which can infect a health worker [12]. There is a paucity of information on occupational exposure in private health care settings, and in HIV designated care centres in the available literature.

The objective of this study is to determine the prevalence of occupational exposure to HIV infection among healthcare workers in PMTCT sites and the outcome will make for policy direction from an informed perspective.

\section{Methods}

\section{Study sites}

Port Harcourt metropolis in Rivers State has designated PMTCT health facilities of public and private ownership. The private and public health facilities offer comprehensive healthcare services to clients. All study sites are reputed for good volume of client turn out and had at least a representative of the healthcare worker of interest whose day to day activity requires their contact with an HIV patient or their body fluid.

An Interviewer Administered Questionnaire was used to assess the occupational exposure to HIV by asking about accidental splashes with patient's body fluids or prick by sharps while carrying out their duty. Also, their risk perception to occupational exposure, the practice of standard precaution procedure as well as the use of personal protective equipment. The availability of safety protocol/regulation and method of waste disposal were also assessed.

\section{Study design}

We conducted a cross-sectional health facility-based study.

\section{Study population}

The study population was made up of healthcare workers such as doctors, nurses, laboratory scientists or technicians and environmental workers whose daily activities require caring for HIV infected patients.

\section{Inclusion criteria}

Healthcare workers in the selected health facility who were included in this study are doctors, nurses and midwives, laboratory scientist or technicians and environmental workers who were on duty and present at the time of visit; and gave their consent.

\section{Exclusion criteria}

Trainee healthcare workers, healthcare workers that had assumed administrative responsibility and those who are less than 6 months into posting at present workplace were excluded from the study.

\section{Sample size calculation}

The sample size of 341 was calculated using the formula,

$$
\mathrm{n}=\frac{Z^{2}{ }_{\alpha} p q}{d^{2}}
$$

Where,

$n=$ the minimum sample size.

$\mathrm{Z}_{\alpha}=$ the standard normal deviate corresponding to level of significance of $5 \%=1.96$.

$\mathrm{d}=$ the desired level of precision, 0.05 .

$p$ = proportion of $\mathrm{HCW}$ exposed to needle stick injury in Northern Uganda $=0.28$ [13]

$\mathrm{q}=1-p=0.72$.

$10 \%$ non-response rate brings $n=341$.

\section{Sampling technique}

Multiple stage sampling technique was used to select the study subjects. 
Stage 1: Health Facility Selection: All 22 public facilities within the study area designated PMTCT sites were sampled and an additional 22 of identified 34 private health facilities were selected by simple random sampling.

Stage2: Selection of health care workers from Health Facility: The study sample size of 341 was divided equally among the 44 selected health facilities giving 6 participants per facility.

Stage 3: Selection of cadre participants:

At the facility, one health care worker was selected by balloting to represent each cadre of health workers among doctors, nurses/midwives, laboratory scientist or technicians and environmental workers. The remaining two health workers were selected randomly from the four cadres of healthcare workers in the facility. Where a facility had six health care workers, all were studied and where less the remaining is made up from another facility.

\section{Pre-testing of data collection tool}

Pre-testing of the questionnaire was conducted on 30 healthcare workers working in five health institutions that were not selected for the study before the actual data collection. Modification of logical sequence, simplicity, and clarity of questionnaire was done using the findings at the pre-test.

\section{Data collection}

Data was collected using a semi-structured Intervieweradministered Questionnaire. The questionnaire had three sections. Section A: socio-demographic characteristics of health care workers such as age, sex and occupation. Section B: Occupational risk exposure to HIV, and Section C: Determinant factors to occupational risk exposure to HIV infection. The questionnaire was partly developed by us and some variables adapted from previous similar published works [1].

\section{Statistical analysis}

We used Epi info 7 and SPSS statistical software to analyse descriptive variables and logistic regression to identify the independent risk factors associated with occupational exposure to HIV among healthcare workers using $p$-value of $<0.05$ as the level of significance.

\section{Results}

Of the 337 health care providers interviewed, 171 (50.7\%) were recruited from public health facilities while. Sixtythree (18.7\%) respondents were doctors, 124 (36.8\%) nurses, 52 (15.4\%) laboratory scientists or technicians, and 98 (29.1\%) were environmental health workers. Study participants were predominantly Christians (336, 99.7\%).

The majority $(243,72.1 \%)$ of the respondents had completed tertiary education. One-third $(125,37.1 \%)$ had worked for 10 years or more, and 246 (73\%) work for an average of $40 \mathrm{~h}$ or more. Seventy-eight (23.1\%) of the respondents were between the ages of 20-29 years, $156(46.3 \%)$ were between the ages of 30-39 years, 75 (22.3\%) were between the ages of $40-49$ years, 24 (7.1\%) were between the ages of 50-59 years and $4(1.2 \%)$ were 60 years old and above. The mean age was $35.9 \pm 8.4$ years Table 1.

The data also depicts that the overall prevalence of occupational exposure to HIV infection among the studied health care providers in PMTCT sites in Rivers State was $45.4 \%$ (Table 2). Among health care workers in the public health facilities, the prevalence of occupational exposure to HIV infection was $40.9 \%$ compared to $50 \%$ reported by those who work in the private health facilities.

The prevalence of occupational exposure to HIV was as high as $69.8 \%$ among doctors and as low as $20.4 \%$ among environmental health workers. Higher prevalence was found among males (53.7\%) than females (43.3\%).

The prevalence increased with the level of education from $23.8 \%$ among those with, at most, secondary education to $53.5 \%$ among those with higher education. It was lower among those with less than 10 years working experience $89(42 \%)$ compared to those with at least 10 years $64(51.2 \%)$.In terms of the number of working hours in a week, the prevalence of occupational exposure was higher for health care workers who worked less than $40 \mathrm{~h}(50.5 \%)$ compared to those who worked $40 \mathrm{~h}$ or more $(43.5 \%)$ in a week.

Age-specific prevalence revealed $15.7 \%$ among healthcare workers aged 40 years and $42.3 \%$ for those between the ages of $30-39$ years then $41.0 \%$ for those between the ages of $20-29$ years.

Less than half of the health care workers, 123(36.5\%) always wear hand gloves in the course of their duty, while 185(54.9) wear hand gloves sometimes and 29(8.6\%) never wear hand gloves (Fig. 1).

Almost all 305 (90.5\%) of the healthcare workers wash their hands all the time, 22(6.5\%) sometime, and $10(3.0 \%)$ never wash hands while on duty. Regarding wiping hands with antiseptics, 224(66.5\%) does it always while 94(27.9\%) sometimes and 19(5.6) never. The face mask was always worn by $117(34.7 \%)$ and $85(25.2 \%)$ never did.

Up to $45(13.3 \%)$ of the respondents never decontaminated instruments immediately after use, $279(82.8 \%)$ always do, while 13(3.9) do some of the times.

A total of 278(82.5) respondents used safety boxes in the disposal of health waste, always as against 32(9.5) who never used a safety box. Regarding wearing personal protective equipment, only $168(49.0 \%)$ wear protective shoes, 29(8.6\%) use heavy duty gloves, and much less 23 $(6.8 \%)$ wear aprons while at work. 
Table 1 Characteristics of healthcare workers on the prevalence of occupational exposure to HIV infection in PMTCT sites, Port Harcourt, Nigeria

\begin{tabular}{|c|c|c|c|}
\hline Socio-demographics & $\mathrm{N}$ & $\begin{array}{l}\text { Experienced occupational } \\
\text { exposure }\end{array}$ & Percent \\
\hline Health care provider in PMTCT sites & 337 & 153 & 45.40 \\
\hline \multicolumn{4}{|l|}{ Age (Years) } \\
\hline $20-29$ & 78 & 32 & 41.0 \\
\hline $30-39$ & 156 & 66 & 42.3 \\
\hline$\geq 40$ & 103 & 106.7 & 154.7 \\
\hline Mean age \pm SD (years) & & $35.89 \pm 8.4$ & \\
\hline \multicolumn{4}{|l|}{ Occupational cadre } \\
\hline Nurse/midwife & 124 & 64 & 51.6 \\
\hline Environmental health worker & 98 & 20 & 20.4 \\
\hline Doctor & 63 & 44 & 69.8 \\
\hline Laboratory scientist/technician & 52 & 25 & 48.1 \\
\hline \multicolumn{4}{|l|}{ Educational qualification } \\
\hline At most Primary & 23 & 5 & 23.8 \\
\hline Secondary & 71 & 18 & 25.4 \\
\hline Tertiary & 243 & 130 & 53.5 \\
\hline \multicolumn{4}{|l|}{ Years of experience } \\
\hline$<10$ years & 212 & 89 & 42.0 \\
\hline$\geq 10$ years & 125 & 64 & 51.2 \\
\hline \multicolumn{4}{|l|}{ Facility type } \\
\hline Public & 171 & 70 & 40.9 \\
\hline Private & 166 & 83 & 50.0 \\
\hline \multicolumn{4}{|l|}{ Average working hour per week } \\
\hline$<40 h$ & 91 & 46 & 50.5 \\
\hline$\geq 40 h$ & 246 & 107 & 43.5 \\
\hline
\end{tabular}

Figure 2 illustrates the disposal of sharps. Among the study participants, $237(70.3 \%)$ of respondents disposed of sharp equipment into containers set aside for sharps disposal. For some sharps like needles, 48 (14.2\%) participants destroyed used needles in a needle destroyer, 25(7.4\%) bury them in a health facility pit and $3.9 \%$ discard them into general waste containers. Only $4.2 \%$ dispose of sharps by other means that were not mentioned.

The main predictors of occupational exposure to HIV were career cadre. Doctors were more likely to have occupational exposure to HIV than another worker $(\mathrm{AOR}=2.2,95 \%$ C.I $=1.2-4.3, p<0.05)$. On the other hand, environmental health workers appear to be protected when compared to nurses and midwives $(\mathrm{AOR}=0.10,95 \% \mathrm{C}$. $\mathrm{I}=0.02-0.46, p<0.01)$. Finally, there was no difference in risk of occupational exposure to HIV between health workers who work less than $40 \mathrm{~h}$ a week and those who work for at least $40 \mathrm{~h}(0.71(\mathrm{C} . \mathrm{I}=0.44-1.12, p>0.05)$ Table 3.

\section{Discussion}

Our findings indicate that about half of the healthcare workers had been exposed to HIV infection at their duty posts at one time or another in the past one year prior to this study. These findings are consistent and similar to the Bosnia/Herzegovinian, Cameroonian, Saudi Arabian studies on risk of occupational exposure conducted $[11,14,15]$. On the contrary, higher prevalence of occupational exposure to HIV infection among health care workers than the prevalence found in the current study has been reported by several other researchers in sub-Saharan Africa and other parts of the world [16]. But, our findings on prevalence of occupational exposure are above that obtained from similar studies conducted in Poland [10],Kuwait [17], South Korea [18] and Northern Nigeria [2]. This difference in prevalence of HIV observed in previous studies and our present study could be as a result of the difference in the study setting, study design and other methodological techniques. The differential in the level of training received by the health care 
Table 2 Infection prevention and patient safety (IPPS) standards in PMTCT sites Port Harcourt, Nigeria

\begin{tabular}{|c|c|c|}
\hline Variable & Frequency & Percent \\
\hline \multicolumn{3}{|c|}{ Health workers who trained on IPPS $(n=337)$} \\
\hline Yes & 250 & 74.2 \\
\hline No & 87 & 25.8 \\
\hline \multicolumn{3}{|c|}{ Health care workers who need training on IPPS $(n=337)$} \\
\hline Yes & 330 & 98 \\
\hline No & 7 & 2 \\
\hline \multicolumn{3}{|c|}{ Health care worker last training on IPPS $(n=250)$} \\
\hline Less than a year & 114 & 45.6 \\
\hline More than a year & 136 & 54.4 \\
\hline \multicolumn{3}{|c|}{ PPE available for Healthcare worker use at PMTCT facility $(n=337)$} \\
\hline Yes & 262 & 77.7 \\
\hline No & 75 & 22.3 \\
\hline \multicolumn{3}{|c|}{ PPE regularly supplied at facility $(n=262)$} \\
\hline Yes & 176 & 67.2 \\
\hline No & 86 & 32.8 \\
\hline \multicolumn{3}{|c|}{ PEP available at PMTCT facility $(n=337)$} \\
\hline Yes & 188 & 55.8 \\
\hline No & 149 & 44.2 \\
\hline \multicolumn{3}{|c|}{ Someone available to administer PEP at facility $(n=188)$} \\
\hline Yes & 176 & 93.6 \\
\hline No & 12 & 6.4 \\
\hline \multicolumn{3}{|c|}{ Health care workers with access to PEP at facility $(n=337)$} \\
\hline Yes & 183 & 54.3 \\
\hline No & 154 & 45.7 \\
\hline \multicolumn{3}{|c|}{ Presence of reporting system for occupational exposure $(n=337)$} \\
\hline Yes & 206 & 61.1 \\
\hline No & 131 & 38.9 \\
\hline
\end{tabular}

workers in different study settings could also contribute to the variation.

It was also found that the prevalence of occupational exposure to HIV infection was higher among health care workers in private owned health facilities than their counterparts in the public health facilities; same finding was observed in a similar study conducted in Cameroon in 2018 [11]. Higher prevalence observed among health care workers in private health facilities might be due to the fact that private health facilities are profit-oriented. Private health facilities are likely to function with reduced manpower and possible extended work hours per week in order to maximize profit especially in the phase of prevailing economic challenges in Nigeria. In the phase of present economic realities, the private health care facilities may not be living up to the expectations of ensuring their healthcare workers' adherence to standard health and safety regulations in terms of providing protective tools and training on standard infection prevention techniques. On the other hand, the public health facilities attract support from donor agencies which include procurement of safety tools for healthcare workers as well as periodic training. This support may not be readily available at the private facilities because of the more corporate profile and patient selective nature of private health facilities compared to public health facilities.

The risk of transmission of HIV infection from patient to healthcare worker has been shown by previous studies to be $0.3 \%$ in percutaneous exposure and $0.09 \%$ in muco-cutaneous exposure [19]. Contact with potentially infectious body fluid in both private and public facilities was found to be the commonest route of exposure to HIV infection in this study and it represents a substantive means of HIV transmission to a healthcare worker [20]. However, this finding is different from other studies where sharp injuries were found to be the commonest [15]. This outcome may be due to the fact that activities relating to dealing with sharps are more common among healthcare workers compared to dealing with activities that may cause splashes from body fluids. Other important risk factors to occupational exposures which were also found in this study and that could influence the experience of healthcare workers occupational exposure to HIV infection are lack of training on infection prevention and patient safety, unavailability and/or irregular supply of personal protective equipment, and inadequate post-exposure prophylaxis and shortages of personnel to administer post-exposure prophylaxis. The existence of poor infection prevention modalities exposes healthcare workers to HIV infection in PMTCT setting [21]. PMTCT sites at all times ought to function with the highest levels of infection prevention and control, given their nature as a specialized site where healthcare workers care for confirmed HIV positive patients and are at higher risk of contracting HIV compared to health workers in other non-HIV special-care health facilities either private or public.

In addition, we found that healthcare workers whose working hours were greater than $40 \mathrm{~h}$ were at higher risk of sustaining occupational exposure to HIV through percutaneous injuries and muco-cutaneous contaminations compared with other healthcare workers is not unique as similar study reported same in Mongolia [22]. This is because fatigue and exhaustion could lead to lack of concentration and can further predispose the healthcare worker to occupational exposure.

Some of the facilities studied had no established system for reporting occupational exposures. This was similar to the situation reported in areas of comparable resource setting [23]. The findings where a quarter of our study participants received no training on prevention of occupational exposure and almost all the 


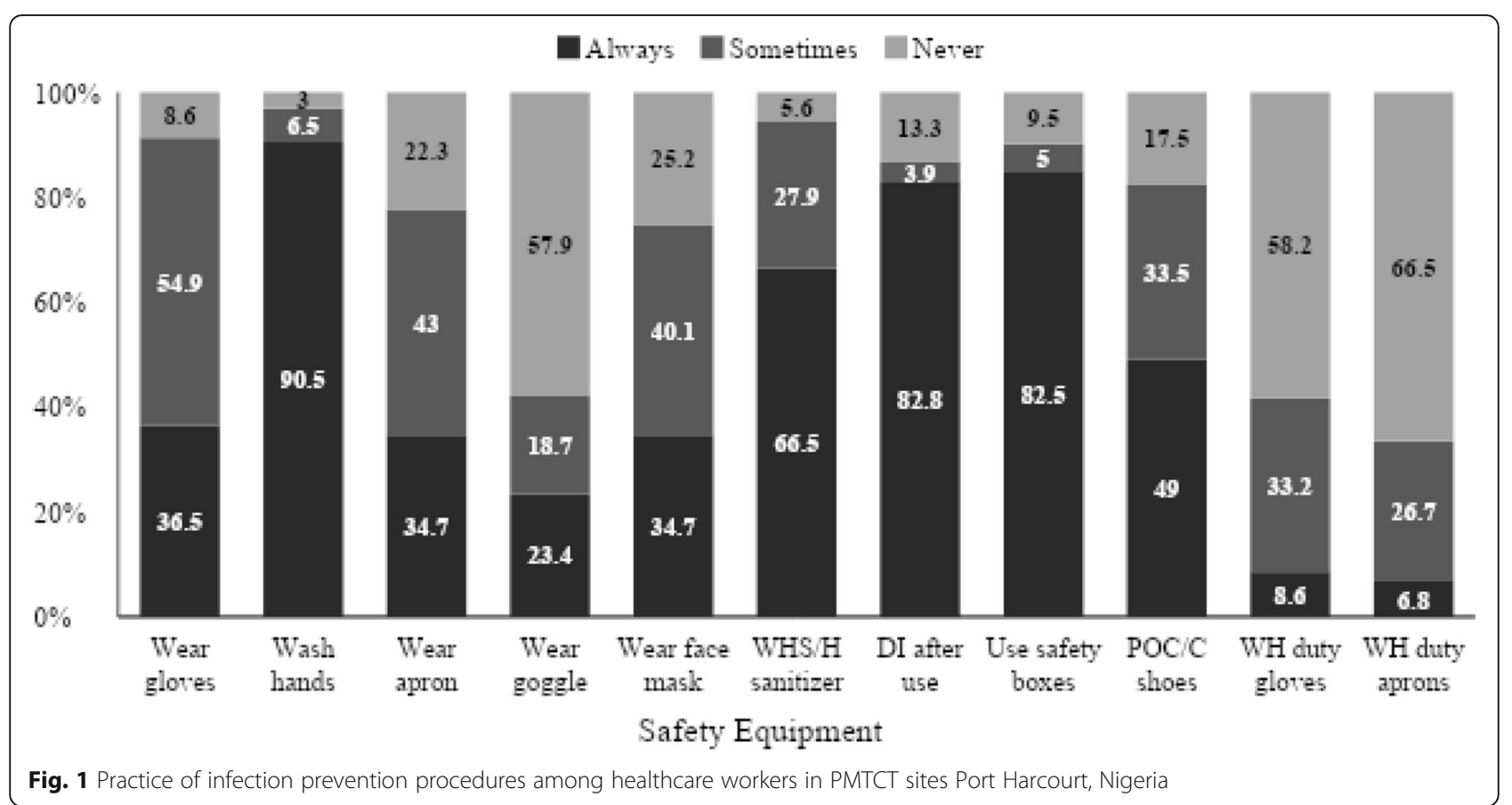

participants wished to be trained on infection prevention and control is worrisome. These findings on deficient training on infection prevention are comparable to outcomes from similar studies in sub Saharan Africa [21]. The display of infection prevention and patient safety signs in health facilities are critical to attitudes of healthcare workers towards infection prevention and patient safety practices. Our research indicates that about fiftypercent of the studied PMTCT sites had guidelines for infection prevention and patient safety readily on display. This situation is a common practice among health facilities in other similar studies in Africa [24, 25].

The important predictors of occupational exposure found in this study were; cadre of health care workers and length of working hours [26]. Doctors were found to be at higher risk compared to other cadre of healthcare workers. This finding differs from findings from other studies where nurses were found to be at higher risk of occupational exposure [16, 27, 28]. High risk found among doctors in this study could be attributed to the fact that they are particularly involved in carrying out invasive procedures, doing veno-puncture and repair of episiotomy.

\section{Limitation of study}

Potential limitation of study includes self-report rather than records review which is a more reliable means of evaluation of occupational exposure as healthcare workers are bound to report socially accepted information. The ability to recall

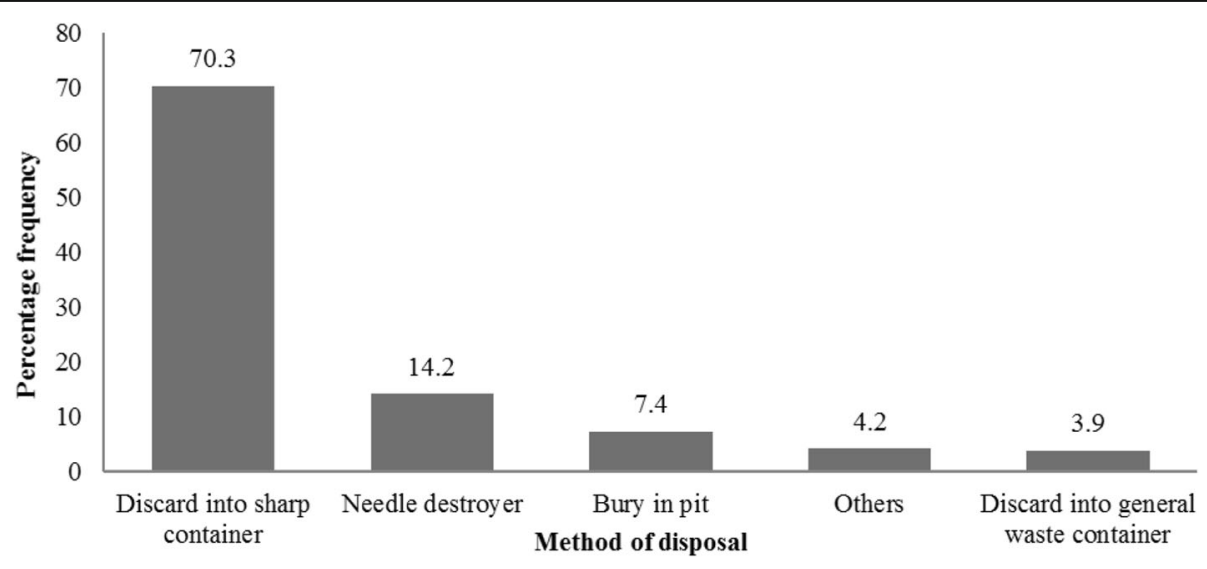

Fig. 2 Sharps disposal methods in PMTCT sites, Port Harcourt, Nigeria 
Table 3 Prevalence and determinants of occupational exposure to HIV infection among healthcare workers in PMTCT sites Port Harcourt, Nigeria

\begin{tabular}{|c|c|c|c|c|}
\hline Factors assessed & Exposed (\%) & Total & $\mathrm{OR}(\mathrm{Cl})$ & $\mathrm{AOR}(\mathrm{Cl})$ \\
\hline \multicolumn{5}{|l|}{ Age } \\
\hline $20-29$ & $32(41.0)$ & 78 & $1.65(0.91-2.99)$ & $1.78(0.86-3.71)$ \\
\hline $30-39$ & $66(42.3)$ & 156 & $1.56(0.95-2.58)$ & $1.80(0.99-3.28)$ \\
\hline $40 \geq$ & $55(53.4)$ & 103 & 1 & 1 \\
\hline \multicolumn{5}{|l|}{ Occupational cadre } \\
\hline Doctor & $44(69.8)$ & 63 & $2.17(1.14-4.13)^{c}$ & $2.22(1.16-4.25)^{c}$ \\
\hline Nurse/midwife & $64(51.6)$ & 124 & $0.24(0.13-0.44)^{a}$ & $0.10(0.02-0.46)^{b}$ \\
\hline Laboratory scientist/technician & $25(48.1)$ & 52 & $0.87(0.45-1.66)$ & $0.87(0.45-1.68)$ \\
\hline Environmental health worker & $20(20.4)$ & 98 & 1 & 1 \\
\hline \multicolumn{5}{|l|}{ Educational qualification } \\
\hline Completed at least Primary & $5(21.7)$ & 23 & $0.24(0.08-0.67)^{b}$ & $2.85(0.44-18.42)$ \\
\hline Secondary & $18(25.4)$ & 71 & $0.30(0.16-0.53)$ & $2.77(0.57-13.29)$ \\
\hline Tertiary & $130(53.5)$ & 243 & 1 & 1 \\
\hline \multicolumn{5}{|l|}{ Years of experience } \\
\hline$<10$ years & $89(42.0)$ & 212 & $1.45(0.93-2.26)$ & $0.94(0.55-1.63)$ \\
\hline$\geq 10$ years & $64(51.2)$ & 125 & 1 & 1 \\
\hline \multicolumn{5}{|l|}{ Facility type } \\
\hline Public & $70(40.9)$ & 171 & $0.693(0.45-1.07)^{d}$ & $0.71(0.44-1.12)$ \\
\hline Private & $83(50.0)$ & 166 & 1 & 1 \\
\hline \multicolumn{5}{|l|}{ Average working hour per week } \\
\hline$<40 \mathrm{~h}$ & $46(50.5)$ & 91 & $0.75(0.47-1.22)$ & $0.53(0.30-0.92)$ \\
\hline$\geq 40 \mathrm{~h}$ & $107(43.5)$ & 246 & 1 & 1 \\
\hline
\end{tabular}

${ }^{a}$ Significant at $0.1 \% ;{ }^{b}$ Significant at $1.0 \% ;{ }^{c}$ Significant at $5.0 \% ;{ }^{\mathrm{d}}$ Significant $10.0 \%$

occupational exposure in the past is also a limitation. We adjusted for this by training interviewers and limiting the period of exposure within one year. Result interpretations and findings from this study may not be generalised beyond PMTCT sites because of the cross-sectional nature of study design.

\section{Conclusion}

The prevalence of occupational exposure to HIV infection among healthcare workers in PMTCT sites within Port Harcourt metropolis was high. Occupational exposure of health care workers to HIV infection is predicated upon the professional cadre of the health worker and high weekly working hours. In addition, the healthcare worker knowledge and adherence to the practice of infection prevention and patient safety is low. Also, despite the availability of protective equipment, all cadre of studied healthcare workers at one point attended to patients without protecting themselves. Some healthcare workers dispose of sharps instruments inappropriately. This implies that all health workers are at risk of HIV infection. Therefore, immediate training of healthcare workers on HIV infection prevention is recommended especially in privately owned PMTCT health facilities. There is also need to enforce the display of infection prevention guidelines and protocol in the PMCTC sites within the constant reach and visualization of healthcare workers. All these are necessary to ensure the safety and protection of healthcare workers thereby making the fight against HIV transmission holistic.

\section{Abbreviations}

AIDS: Acquired Immune Deficiency Syndrome; AOR: Adjusted Odds Ratio; Cl: Confidence Interval; HIV: Human Immune Virus; NFELTP: Nigeria Field Epidemiology and Laboratory Training Program; PLA: People Living with AIDS; PMTCT: Prevention of Maternal to Child Transmission of HIV; SD: Standard Deviation; SPSS: Special Package Statistical Software

\section{Acknowledgements}

The authors would like to appreciate Dr. Magbagbeola D. Dairo for his support and encouragement. We would especially acknowledge the NFELTP facilitators and host of others for their intellectual contributions towards the completion of this research. We are grateful to Dr. Mrs. Gloria Worugji for editing this paper

\section{Authors' contributions}

$\mathrm{NA}$ and Al made substantial contributions to the design of the study. NA was the principal investigator who designed data collection tools, collected data, analysed and interpreted data. AA assisted with data analysis and draft of manuscript. Al, AA, IS, MD, PN and EA revised article critically and made 
several important intellectual contributions. All authors' have read and approved the manuscript.

\section{Funding}

No funding was secured for this study.

\section{Availability of data and materials}

The dataset used to produce this manuscript can be obtained from the corresponding author on reasonable request.

\section{Ethics approval and consent to participate}

We obtained ethical approval from the Scientific and Ethical Committee in the Department of Planning Research and Statistics of Rivers State Ministry of Health in a letter with reference number MH/PRS/391/Nol. 2/381. We obtained informed verbal consent from each participant as was approved by the ethical committee.

\section{Consent for publication}

Not applicable because data which could affect individual privacy was not indicated in the manuscript.

\section{Competing interests}

The authors declare no competing interest in connection with this paper.

\section{Author details}

${ }^{1}$ Nigeria Field Epidemiology and Laboratory Training Program (NFELTP), 50 Haile Selassie Street, Asokoro, Abuja, Nigeria. ${ }^{2}$ Department of Epidemiology and Medical Statistics College of Medicine, University of Ibadan, Ibadan, Nigeria. ${ }^{3}$ Department of Community Medicine, Ahmadu Bello University Zaria, Kaduna State, Nigeria.

Received: 20 July 2019 Accepted: 16 March 2020

Published online: 06 April 2020

\section{References}

1. Tesfay FA, Habtewold TD. Assessment of prevalence and determinants of occupational exposure to HIV infection among healthcare Workers in Selected Health Institutions in Debre Berhan town, north Shoa zone, Amhara region. Ethiopia. 2014;2014:2014.

2. Amoran OE. Occupational exposure, risk perception and access to prophylaxis for HIV/AIDS infection among health Care Workers in Northern Nigeria. Br J Med Med Res. 2013;3(2):275-87.

3. National Agency for the Control of AIDS (NACA), Federal Republic of Nigeria. Global AIDS Response Country Progress Report 2014. Available at http://www.unaids.org/sites/default/files/country/documents/NGA-narrativereport-2014 (accessed last 15 April, 2019).

4. Nigerian HIV/AIDS Indicator and Impact Survey (NAllS) National Summary Sheet March 2019. Available at http://www.naca.gov.ng/naiis-nationalsummary-sheet/ (accessed last 15 April,2019).

5. Gebresilassie A, Kumei A, Yemane D. Community Medicine \& Health Education Standard Precautions Practice among Health Care Workers in Public Health Facilities of Mekelle Special Zone, Northern Ethiopia. J Community Med Health Educ. 2014:4(3):281

6. Beyene T, Tadesse S. Predictors of occupational exposure to HIV infection among healthcare workers in southern Ethiopia. Int J Infectious Control. 2014; $\vee$ 10:i3

7. Reda A A., Fisseha S, Mengistie B, Vandeweerd JM. Standard precautions: occupational exposure and behavior of health care workers in Ethiopia. PLoS One 2010:5(12):1-6.

8. Mashoto KO, Mubyazi GM, Mushi AK. Knowledge of occupational exposure to HIV: a cross sectional study of healthcare workers in Tumbi and Dodoma hospitals, Tanzania. BMC Health Serv Res. 2015;15(1):1-6.

9. Gumodoka B, Favot I, Berege ZA, Dolmans WM. Occupational exposure to the risk of HIV infection among health care workers in Mwanza region, United Republic of Tanzania. Bull World Health Organ. 1997;75:133-40

10. Garus-pakowska A. Behaviors and Attitudes of Polish Health Care Workers with Respect to the Hazards from Blood-Borne Pathogens: A QuestionnaireBased Study. 2019;1-13.

11. Domkam IK, Sonela N, Kamgaing N, Takam PS, Gwom L, Michel T, et al. Prevalence and risk factors to HIV-infection amongst health care workers within public and private health facilities in Cameroon. 2018;8688:1-7.
12. Wu Q, Xue XF, Shah D, Zhao J, Hwang LY, Zhuang GH. Knowledge, attitude, and practices regarding occupational HIV exposure and protection among health Care Workers in China. J Int Assoc Provid AIDS Care. 2016;15(5):363-9.

13. Odongkara BM, Mulongo G, Mwetwale C, Akasiima A, Muchunguzi HV, Mukasa S, et al. Prevalence of occupational exposure to HIV among health workers in Northern Uganda. Int J Risk Saf Med. 2012;24:103-13 Available from: http://www.ncbi.nlm.nih.gov/pubmed/22751192.

14. Jahic R, Piljic D, Porobic-jahic H, Custović A. Epidemiological Characteristics of the Accidental Exposures to Blood-Borne Pathogens Among Workers in the Hospital. 2018;72(3):187-91.

15. Samargandy SA, Bukhari LM, Samargandy Shaza S, Bahlas RS, Aldigs EK, Alawi MM, et al. Epidemiology and clinical consequences of occupational exposure to blood and other body fluids in a university hospital in Saudi Arabia. Saudi Med J. 2016;37(7):783-90.

16. Gabr HM, El-Badry AS, Younis FE. Risk factors associated with needlestick injuries among health care workers in Menoufia governorate. Egypt Int J Occup Environ Med. 2018:9(2):63-8.

17. Omar AA, Abdo NM, Salama MF, Al-Mousa HH. Occupational injuries prone to infectious risks amongst healthcare personnel in Kuwait: a retrospective study. Med Princ Pract. 2015:24(2):123-8.

18. Lee JH, Cho J, Kim YJ, Im SH, Jang ES, Kim JW, et al. Occupational blood exposures in health care workers: incidence, characteristics, and transmission of bloodborne pathogens in South Korea. BMC Public Health 2017;17(1):1-8

19. Odongkara BM, Mulongo G, Mwetwale C, Akasiima A, Muchunguzi H V, Mukasa S, et al. Prevalence of occupational exposure to HIV among health workers in northern Uganda. Int J Risk Saf Med [Internet]. 2012;24:103-13.

20. Wyżgowski P, Rosiek A, Grzela T, Leksowski K. Occupational HIV risk for health care workers: risk factor and the risk of infection in the course of professional activities. Ther Clin Risk Manag. 2016;12:989-94.

21. Mossburg S, Agore A, Nkimbeng M, Commodore-Mensah Y. Occupational Hazards among Healthcare Workers in Africa: A Systematic Review. 2019; 85(1):1-13.

22. Markovic-Denic L, Maksimovic N, Marusic V, Vucicevic J, Ostric I, Djuric D. Occupational exposure to blood and body fluids among health-care workers in Serbia. Med Princ Pract. 2015;24(1):36-41.

23. Yi Y, Yuan S, Li Y, Mo D, Zeng L. Assessment of adherence behaviors for the self-reporting of occupational exposure to blood and body fluids among registered nurses: A cross-sectional study. PLoS One. 2018:13(9):1-13.

24. Jain M, Sabharwal ER, Srivastava D. Practices of health care personnel regarding occupational exposure. J Clin Diagnostic Res. 2016;10(11):DC14-7.

25. Isah AM, Igboeli NU, Adibe MU, Ukwe CV. Evaluation of HIV post-exposure prophylaxis (PEP) in a tertiary health institution in South-Eastern Nigeria. J AIDS HIV Res. 2016:8(8):108-13.

26. Abdulmageed SS, Alabbassi F, Alradi M, Alghanaim N, Banjar S, Alnakhli M. Assessment of occupational exposure to sharp injuries among health care workers in king Abdulaziz University hospital. Int J Community Med Public Heal. 2018;5(5):1756-61.

27. Motaarefi $\mathrm{H}$, Mahmoudi H, Mohammadi E, Hasanpour-Dehkordi A. Factors associated with needlestick injuries in health care occupations: a systematic review. J Clin Diagnostic Res. 2016;10(8):IE01-4.

28. Quan $M$, Wang $X$, Wu H, Yuan $X$, Lei $D$, Jiang $Z$, et al. Influencing factors on use of standard precautions against occupational exposures to blood and body fluids among nurses in China. Int J Clin Exp Med. 2015;8(12):22450-9.

\section{Publisher's Note}

Springer Nature remains neutral with regard to jurisdictional claims in published maps and institutional affiliations. 